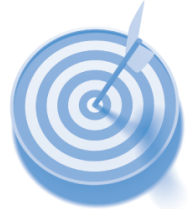

A J Shaw, T G Harrison, $K \mathrm{~L}$ Shallcross, $\mathbf{S} \mathrm{J}$ Williams and D E Shallcross* Bristol ChemLabS School of Chemistry University of Bristol Bristol BS8 1TS

*d.e.shallcross@bris.ac.uk

\section{On the impact of the Bristol ChemLabs' outreach programme on admissions to the School of Chemistry}

\begin{abstract}
Analysis of the average number of applicants received from schools that engaged in the Bristol ChemLabS Outreach program prior to a student's application with those that did not engage, shows a significant increase in applicants from engaged schools. The significance is weaker when just Post 16 students are considered but this is almost certainly due to a smaller sample size. When this analysis was inspected in terms of the distance of the school from the University of Bristol, there was an increase in the number of applicants from engaged schools irrespective of distance. However, a statistically significant increase was observed for schools within 50 miles of the University from an analysis of just Post 16 students. Students who applied to the department from an engaged school were more likely to accept an offer and also to make the department their firm acceptance. A slightly higher number of applications that were rejected came from engaged schools too. There are two possible reasons; first, the engagement may have encouraged more students who did not have the required entry qualifications. Second, during the period of analysis, the overall entry grades went up by one grade each year. Such a dramatic rise was probably the reason for the slightly elevated numbers.
\end{abstract}

\section{Introduction}

The numbers of applicants and acceptances from universities have been increasing overall in recent years ${ }^{1}$. However, there has been concern for some time about the decline in interest from young people in studying science and in pursuing scientific careers ${ }^{2}$. Interest in science outreach related activities has risen based on this, where the engagement activities often are concerned with encouraging interest in science and scientific careers ${ }^{3-7}$.

Following on from the original goals of the outreach program started in 2000, the Bristol ChemLabS Outreach activities ${ }^{8-15}$ have the objective of promoting Chemistry on a national and even an international basis, without any emphasis on recruitment to the School of Chemistry at Bristol. In this way, activities are free from advertising and staff are under no pressure to compare recruitment statistics with outreach activity. This has been a very helpful approach and has allowed the Outreach team to take a long-term view in terms of their planning. However, after five years of the Bristol ChemLabS Outreach program it is interesting and appropriate to look back and compare these activities with data on applications and admissions to the School of Chemistry. Has the Outreach program had any impact on recruitment? This study compares applications from schools that have and have not engaged with Bristol ChemLabS in the years prior to the application being made and look at trends.

\section{Research Questions}

- What are the effects, if any, of a school's engagement with the Bristol ChemLabS' outreach program on the number of students applying to study chemistry at the University of Bristol?

- What are the differences, if any, between applicants to the School of Chemistry if the applicant's school had or had not taken part in Bristol ChemLabS outreach activities?

\section{Methods}

Sample

Application data to the School of Chemistry were obtained for the years between 2005 and 2008. This included applications for all chemistry undergraduate courses supplied by the department, for both immediate and deferred starts. Data were supplied in an anonymous format but appropriate for this research. 
The following variables were available in these data:

- Year of Admission cycle

- Entry year applied for

- Course applied for at University of Bristol

- Decision/response at University of Bristol

- Gender

- Local Education Authority

- School

- Institution the applicant attended

These data were merged with information on which schools had engaged in the Bristol ChemLabS Outreach program and a variable was created to indicate this.

The definition of an engaged school included any secondary school that had engaged with Bristol ChemLabS outreach in the years prior to the students' application to the University of Bristol. This grouping takes into account students that may have been affected indirectly through their schools' interaction with Bristol ChemLabS, such as through recommendations by teachers or fellow students.

\section{Data Analysis}

The Statistical Package for the Social Sciences (SPSS) was used to run statistical analysis tests with data. Chi-square tests of independence were used to explore the relationship between engaged and non engaged applicants, and a number of variables. Post-hoc tests were used to further understand results of chi-square tests of independence, when more clarification was necessary. Independent samples t-tests were used to compare groups (engaged and non-engaged schools) in terms of the average numbers of students applying to the School of Chemistry.

\section{Results \& Analysis}

1. Applications analysis

Table 1 shows that engaged schools showed a noticeably higher average number of applicants than schools that had not engaged with Bristol ChemLabS prior to the applications being made, both the Post 16 and complete cohort. An independent samples t-test was used to compare the average number of all applicants for both engaged and non engaged schools over the three years of applications from 2006 to 2008. For the entirety of these three years, engaged schools were found to have significantly higher average numbers of applicants than non-engaged schools $(\mathrm{t}(1370)=-1.981$, $\mathrm{p}=.048$ (two tailed)). For Post 16 students the t-test was bordering on significant ( $t=-1.923, p=.055$ (two tailed)). Since the results are very similar to those obtained for the overall engaged group, reduced sample size could be a factor here.

\section{Applications from Students Attending Schools in Surrounding Areas Engaging with Bristol ChemLabS} When considering the cohort as a whole engaged schools show slightly higher average numbers of applicants than non-engaged schools. However, the differences were not statistically significant for any of the areas when independent sample t-tests were used to compare the average number of applicants for both engaged and non engaged schools in each area. In a similar way, just the Post 16 cohort showed that in almost all locations, engaged schools show slightly higher average numbers of applicants than non-engaged schools.

\begin{tabular}{|c|c|c|c|}
\hline $2006-2008$ & All Applicants & Engaged School & $\begin{array}{l}\text { Non Engaged } \\
\text { School }\end{array}$ \\
\hline All students & 2.54 & 3.10 & 2.51 \\
\hline A level students & 2.54 & 3.30 & 2.52 \\
\hline
\end{tabular}

Independent samples t-tests were used to establish whether the difference in average number of applicants from engaged and non-engaged schools were significant. Table 2 shows the p-values that indicate that there are a significantly higher number of applicants per school for engaged schools within 50 miles of the University of Bristol, compared with schools in the same area that had not been engaged.

Table 2: Average number of applicants per school to the School of Chemistry based on school location during 2006 to 2008 * indicates difference is significant at the 95\% confidence level or above

\begin{tabular}{|l|l|l|l|l|}
\hline $\begin{array}{l}\text { Distance from University of } \\
\text { Bristol }\end{array}$ & All Applicants & Engaged & Non-engaged & Sig. (2-tailed) \\
\hline $\mathbf{5 0 ~ M i l e s ~}$ & & & & \\
Post 16 & 2.60 & 3.77 & 2.41 & $.017^{*}$ \\
All & 2.60 & 3.00 & 2.43 & \\
\hline Within 100 miles & & & & .29 \\
Post 16 & 2.82 & 3.30 & 2.77 & \\
All & 2.82 & 3.21 & 2.74 & .46 \\
\hline Between 50 and 100 miles & 3.01 & 2.36 & 3.05 & .29 \\
Post 16 & 3.01 & 3.62 & 2.95 & .29 \\
All & & 3.27 & 2.44 & \\
\hline Over 100 miles & 2.45 & 2.85 & 2.44 & \\
All 16 & 2.45 & & & \\
\hline
\end{tabular}


3. Gender of Applicants and School Engagement Schools engaging with Bristol ChemLabS had a slightly larger proportion of males applying to study chemistry at the University of Bristol than schools that had not engaged. The Chi-square test for independence indicated no significant association between school engagement and gender for the whole cohort, $x 2(1, n=3585)=2.9, p=.09$ or from the group of just $A$ level students, $x 2(1, n=3585)=3.8, p=.06$.

\section{Decision on Students' Applications}

Analysis of applications showed that students from engaged schools were more likely to accept the offer made to them and indeed were more likely to make the department their firm acceptance. A downside was that engagement encouraged more students from those schools to apply who did not have the required entry qualifications, leading to a slightly higher number of rejections. During this time, the School of Chemistry raised their entry requirement by at least one Post 16 grade each year. This rapidly increasing entry requirement could also be responsible for the increase in rejections.

average, with more students than average taking triple science and Post 16 chemistry. This may mean that they have more students applying for university generally, and more students applying for chemistry or chemistry related subjects. This wouldn't necessarily explain an increase in applications to Bristol specifically, but could be a potential avenue for future research to see if engaged schools do have more students applying for chemistry at university, and whether or not those students show a bias towards applying to Bristol.

\section{Applications from Students Attending Schools in Surrounding} Areas Engaging with Bristol ChemLabS

A comparison of the average number of applicants per school to the School of Chemistry at the University of Bristol was made, isolating schools within 50 miles of the university, schools within 100 miles of the university, schools within 50 to 100 miles of the university and schools over 100 miles away. In a comparison of all engaged and non-engaged schools, the findings demonstrated that in all areas, the average number of students applying to the School of Chemistry was higher in engaged schools than non-engaged schools. However, independent samples t-tests demonstrated that this difference was not significant in any area, near or far from the university. Comparing only those schools with engaged Post 16 students and those not engaging Post 16 students, the findings showed that in most areas, the average number of students applying to the School of Chemistry was higher in engaged schools than non-engaged schools. Results from independent samples t-tests indicated that this difference was significant for students from schools within 50 miles of the university. This suggests that students that potentially may not have applied to the University of Bristol from this area (perhaps because it was too close to home) did so after experiencing the university for themselves. Across the whole university the number of students applying from the southwest of England region is only 8-9\%. The significant association between application and engagement with local schools is particularly encouraging. However, there was a change in the trend for schools between 50 and 100 miles from the university. Although not significant, schools from this area that had not engaged with Bristol ChemLabS had a higher average number of students applying to the University of Bristol than those schools that had engaged. The sample size for this particular analysis was very small, and given this trend does

Another consideration is that schools engaging with Bristol ChemLabS (in fact, all schools that sign up to receive the $\mathrm{CHeMneT}$ newsletter) tend to be better performing than
Table 3: Proportion of applications to study chemistry at the University of Bristol who are males and females from 2006 to 2008

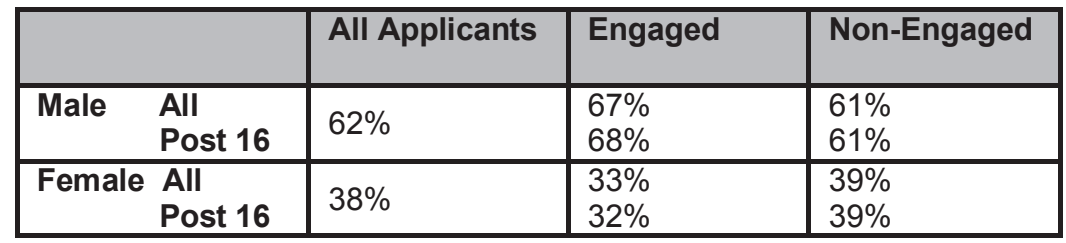

not occur when all engaged schools are used in the comparison, it could be that the small sample size had an impact on this result. 
Gender of Applicants and School Engagement In all applicants to the School of Chemistry, each year around two thirds of applicants are male, and one third female. In a recent report from UCAS, the UK university admissions service $^{1}$ analysis of university applications from 2002 to 2007 showed nationally around $60 \%$ of applications to study chemistry were from males. Comparison of applicants from engaged and non-engaged schools showed little difference in the proportion of males to females, both for all engaged schools and just those with engaged Post 16 students. Since only a few of the activities offered by Bristol ChemLabS are specifically to encourage female students' interest in chemistry (and these are at Key Stages 2-4), it is perhaps unsurprising that there is no change in this. The positive interpretation of this finding is that the activities of Bristol ChemLabS may be appealing to both males and females in equal measures, since the ratios of gender were not significantly different.

Decision on Students' Applications Although there was no significant result in the post-hoc test for the numbers of engaged and non-engaged applicants declining a place at the School of Chemistry, inspection of the original results suggest that applicants from engaged schools are less likely to decline a place if they are offered one. The standardised residual for this group, (students from engaged schools that declined a place) although not statistically significant, shows there were less than expected numbers of applicants in this group. This may have been the case because many of these students may have had direct experience of the University of Bristol and the School of Chemistry, and so would be more likely to apply for a place only if they were reasonably sure they would want to attend the university. A similar pattern of results was observed in the comparison of schools with engaged Post 16 students and schools without, although this was not significant in statistical tests. Again, this may be due to the reduced sample size for this particular group.

\section{Applicants' School Type and School Engagement}

There was no significant difference between applicants from engaged and non engaged schools in the proportion of applicants coming from state and independent schools, in both a comparison involving all engaged schools and that involving only schools with engaged Post 16 students. It has been established that Bristol ChemLabS has been engaging with a similar proportion of state and independent schools to that in the whole of the UK. The positive interpretation of this finding is that the activities that Bristol ChemLabS provide do not seem to appeal to students from one type of school more than another. It is important to bear in mind that this comparison did not take into account those students that had gone on to an FE institution to undertake their Post 16 studies, as it was not possible to tell what type of school they originally attended from the data available.

\section{Summary}

From 2006 to 2008, schools that had engaged with Bristol ChemLabS (with any age group) had a significantly higher average number of applicants than schools that had not engaged. Although this was only a small difference, it is an encouraging finding that suggests engaging in chemistry-related activities like those offered by Bristol ChemLabS may have an effect on students' further study decisions.

\section{Further Research}

If further research were to be undertaken, it would be useful to increase the sample size of applicants, in order to obtain more reliable results, and give a better chance of being able to obtain a significant result if there are real differences between applicants from engaged and non-engaged schools. Further research would also be interesting into the places that students from schools engaging with Bristol ChemLabS go. Although this research showed a slight increase in applicants to the School of Chemistry at the University of Bristol, it would be interesting to research whether engaged schools have an overall increase in students applying for chemistry related degrees at any university. It would be useful to gain information from both engaged and non-engaged schools on where and what university courses (including non-chemistry courses at Bristol) their students apply for, to establish if there is any overall difference.

\section{Acknowledgments}

We would like to thank the Higher Education Funding Council for England for their funding of the Bristol ChemLabS CETL project. Dudley Shallcross also thanks the UK's Higher Education Academy for a National Teaching Fellowship.

\section{References}

1. UCAS, Research Team (2008) 'Trends in Applications, Applicants and Acceptances to Mathematics, Physics, Engineering and Biology between the Years 2002 and 2007', DIUS Research Report, 08-21.

2. Osborne, J., Simon, S., Collins, S. (2003) 'Attitudes Towards Science: A Review of the Literature and its Implications', International Journal of Science Education, 25(9), 1049-1079.

3. Beck, M.R., Morgan, E.A., Strand, S.S. and Woolsey, T.A. (2006) 'Volunteers Bring Passion to Science Outreach', Science, 314, 1246-1247.

4. Flynn, N. (2005) 'Science Days: An Interdisciplinary Program' Journal of Chemical Education, 82, 1483-1485.

5. Bell, R.L., Blair, L.M., Crawford, B.A. and Lederman, N.G. (2003) 'Just Do It? Impact of a Science Apprenticeship Program on High School Students' Understandings of the Nature of Science and Scientific Inquiry', Journal of Research in Science Teaching, 40(5), 487-509

6. Melber, L.M. (2003), 'Partnerships in Science Learning: Museum Outreach and Elementary Gifted Education', Gifted Child Quarterly, 47(4), 251-258. 
7. Gibson, H.L. and Chase, C. (2002), 'Longitudinal Impact of an Inquiry-Based Science Program on Middle School Students' Attitudes toward Science', Science Education, 86(5), 693-705.

8. Harrison T.G., Davey W.B. and Shallcross D.E. (2011), 'Making Better and Wider Use of Undergraduate Teaching Laboratories in the Promotion of Chemistry in the UK', submitted to New Directions.

9. Harrison T. G., Shaw A. J., Shallcross K. L., Williams S. J. and Shallcross D. E. (2010), School-University partnerships: Lessons learned from 10 years of Spectroscopy for Teachers and Post 16 Students, New Directions, 6, 72-76.

10. Harrison T.G. and Shallcross D.E. (2010), What should be Expected of Successful Engagement between Schools, Colleges and Universities? School Science Review, 91(35), 97-102.

11. Shaw A.J., Harrison T.G., Croker S.J., Medley M.I., Sellou L. Shallcross K.L., Williams S.J., and Shallcross D.E. (2010), University-School partnerships: On the impact on students of Summer Schools (for school students aged 17-18) run by Bristol ChemLabS, Acta Didactica Napocensia 3(4), 35-48.

12. Shaw, A.J., Harrison, T.G., Croker, S.J., Medley., M.I., Shallcross, K.L., Williams, S.J. and Shallcross, D.E. (2010), University-School partnerships: Polymer Chemistry days run at a University for 14-15 year olds and their impact on attitudes to Science, Acta Didactica Napocensia, 3 (1), 19-26.

13. Shaw, A.J., Harrison, T.G., Shallcross, D.E. and Medley, M.I. (2009), Chemistry Inreach: Engaging with University Employees' Children within a Chemistry Department, Acta Didactica Napocensia, 2 (4), 107-112.

14. Harrison T. G., Hughes L. and Shallcross D. E. (2009), 'Jersey Schools Science Week: An Outreach Case Study', New Directions 4, 30-33 (2009).

15. Tuah J., Harrison T.G. and Shallcross D.E. (2010), 'A Review of the Use of Demonstration Lectures in the Promotion of Positive Attitudes towards, and the Learning of Science with reference to a 'A Pollutant's Tale', a demonstration lecture on air quality and climate change', The Romanian Journal of Education 1, 75-80 (2010).

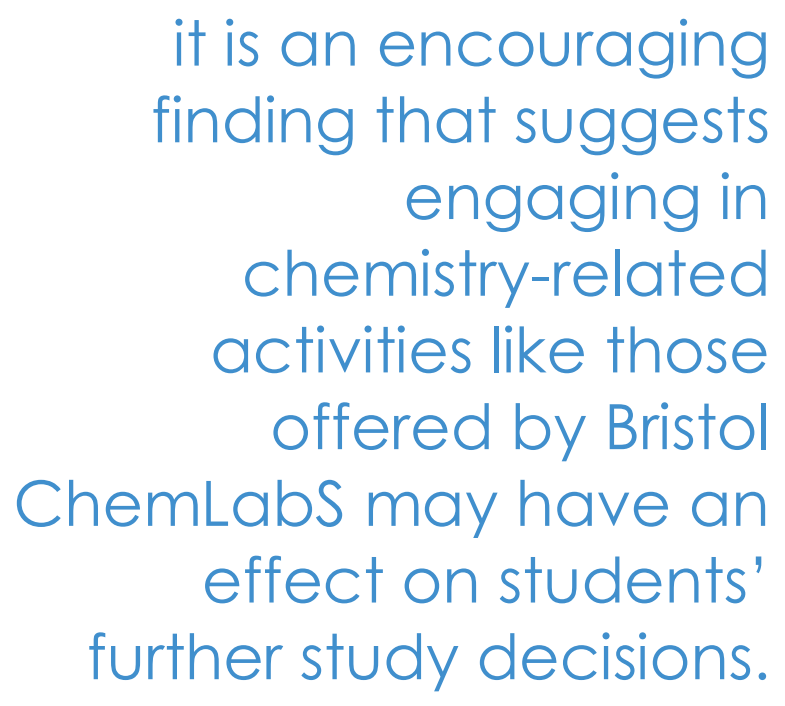

